\title{
Roles and Functions of Community Health Workers in Primary Care
}

Andrea L. Hartzler, $P b D^{1}$

Leah Tuzzio, $\mathrm{MPH}^{2}$

Clarissa Hsu, PbD ${ }^{2}$

Edward H. Wagner, MD, MPH

'Department of Biomedical Informatics and Medical Education, University of Washington, Seattle, Washington

${ }^{2}$ Kaiser Permanente Washington Health Research Institute, Seattle, Washington

\section{sim MORE ONLINE www.annfammed.org}

Conflicts of interest: authors report none.

\section{CORRESPONDING AUTHOR}

Andrea L. Hartzler, PhD

Department of Biomedical Informatics and Medical Education

University of Washington

815 Republican St. C231 Box 2358047

Seattle, WA 98195-8047

andreah@uw.edu

\begin{abstract}
Community health workers have potential to enhance primary care access and quality, but remain underutilized. To provide guidance on their integration, we characterized roles and functions of community health workers in primary care through a literature review and synthesis. Analysis of 30 studies identified 12 functions (ie, care coordination, health coaching, social support, health assessment, resource linking, case management, medication management, remote care, follow-up, administration, health education, and literacy support) and 3 prominent roles representing clusters of functions: clinical services, community resource connections, and health education and coaching. We discuss implications for community health worker training and clinical support in primary care.
\end{abstract}

Ann Fam Med 2018;16:240-245. https://doi.org/10.1370/afm.2208.

\section{INTRODUCTION}

I ncreased health care costs and demand have accelerated the need for resource-saving approaches that improve access to and delivery of primary care services. We define community health workers in primary care (CHW-PCs) as trained individuals with limited to no formal medical education who provide patient-facing support and services in primary care. CHW-PCs carry out functions that are person-centered, support teambased care, address social determinants of health, and promote health care access, patient engagement, and outcomes. ${ }^{1-4}$ Historically, these frontline health workers have been particularly effective when they share ethnicity, language, socioeconomic status, and life experiences with communities they serve, ${ }^{5}$ reflecting peer support. ${ }^{6}$ A growing body of research illustrates diverse ways that community health workers, best known for their role in community and global settings, ${ }^{5,7,8}$ can be utilized in primary care. Despite their potential to contribute as care team members, ${ }^{9-12} \mathrm{CHW}-\mathrm{PC}$ remain largely underutilized. ${ }^{7,11}$ Guidance is needed on ways to best promote and expand CHW-PCs. CHW-PC roles vary across clinics, with numerous job titles and duties, making it difficult to identify best practices. ${ }^{2,3}$ Perspectives vary on what CHW-PCs do and their training and clinical support needs.

\section{METHODS}

Following PRISMA guidelines, ${ }_{1}^{13}$ we characterized patient care roles and functions of CHW-PCs in US primary care through a systematic mixed studies review. ${ }^{14,15}$ Supplemental Appendix 1, http://www.annfammed. org/content/16/3/240/suppl/DC1/, details the inclusion criteria, search strategy, quality assessment, data extraction, and PRISMA flow diagram of our systematic review. Briefly, we searched and screened articles for eligibility, assessed article quality using the Mixed Methods Appraisal Tool (MMAT) ${ }_{1}^{16}$ and extracted data on characteristics of CHW-PCs from articles meeting inclusion criteria. We used extracted data to: (1) qualitatively classify functions CHW-PCs perform using a modified Delphi card sort, ${ }^{17}$ and (2) quantitatively identify roles through k-means cluster analysis of 
functions. ${ }^{18}$ The card sort involved writing descriptions of what CHW-PCs do, which coauthors grouped by similarity into functional categories. To identify roles that involved multiple functions, we described each study as a binary vector of functions (ie, each function was marked as present/absent) and clustered vectors, varying the number of clusters $(\mathrm{K})$ until reaching the best fit using silhouette width. ${ }^{19}$

\section{RESULTS}

Thirty studies met inclusion criteria (Supplemental Appendix 2, available at http://www.annfammed.org/ content/16/3/240/suppl/DC1/). ${ }^{20-50}$ We combined articles about the same study ${ }^{33,34}$ and added detail from reference lists. ${ }^{51-56}$ Study designs included qualitative, quantitative (ie, randomized controlled trials, nonrandomized, or descriptive designs), and mixed methods. Most studies $(24 / 30)$ scored moderate to high quality (MMAT $\geq 50 \%$ ).

Community health workers in primary care characteristics were diverse (Supplemental Appendix 3, available at http://www.annfammed.org/content/16/3/240/ suppl/DC1/), with over one-half targeting racial, ethnic, or underserved groups. "Most had administrative structures supporting their work, such as designated staff $^{32,43}$ and regular team meetings. ${ }^{22,36}$ In addition to patient visits and phone calls, in one-third of studies CHW-PCs extended the reach of care teams through home visits ${ }^{\dagger}$ and documentation in electronic health records $\mathrm{s}^{20,25,33,36,43,44}$ or registries. ${ }^{21,23,24,33-35,37,38}$

\section{Functions}

We qualitatively identified 12 distinct CHW-PC functions representing patient-facing services (Table 1).

\section{Roles}

Based on the distribution of CHW-PC functions across studies, $\mathrm{k}$-means clustering indicated 3 clusters (average silhouette width $=0.23, \mathrm{SD}=0.7$ ). Removing 6 studies with MMAT quality scores $<50 \%{ }^{21,22,28,40,46,50}$ had little impact on clusters (average silhouette width $=0.22$, $\mathrm{SD}=0.05)$. We labeled clusters as CHW-PC roles having similar constellations of functions: clinical services, community resource connections, and health education and coaching (Table 2). Nearly all studies depict multiple functions with some functions more prevalent than others (eg, health coaching, case management).

\section{Clinical Services}

Clinical services focus on health assessment and remote care more than other clusters. ${ }^{21-31}$ This role

*References 25-28,33,35,38,41,42,44,45,47-49

† References 22,24,29,31,32,35,38,40-42,46 also performed other functions, but none provided literacy or social support. Examples include assessment of vital signs, lifestyle, health knowledge, ${ }^{23}$ psychosocial factors, ${ }^{22,26}$ and care through routine exams aided by remote communication with physicians. ${ }^{28}$ These services provide for patient dialog, helping care teams understand patients' health, background, and preferences. ${ }^{22}$ An example is the "community health aid" who provided clinical services in remote Alaskan villages using scripted questions and directed exams for common health problems. ${ }^{24}$

\section{Community Resource Connections}

Community resource connections link patients with community-based services, ${ }^{32-40}$ such as referrals for transportation or food assistance. ${ }^{35}$ Ongoing social support and follow-up phone calls were common, yet remote care, education, and literacy support were uncommon. An example is "promotoras" who screen patients for depression by interviewing them about contextual factors (eg, unemployment) and help resolve those barriers with community referrals (eg, vocational training). ${ }^{37}$

\section{Health Education and Coaching}

Health education and coaching are key functions of the third role. ${ }^{20,41-50}$ Health coaching generally involved motivational interviewing ${ }^{46}$ and action planning to help patients achieve health goals. ${ }^{45}$ Health education typically targeted specific issues, such as cancer screening ${ }^{42,44}$ or self-management of a chronic illness. ${ }^{43}$ Nearly one-half of studies in this cluster provided follow-up and administrative support, yet none included health assessment or remote care. Examples include "peer health coaches" who counsel, teach, and support self-management in low-income diabetics ${ }^{47}$ or "care guides" who facilitate goal setting and care coordination. ${ }^{20}$

\section{DISCUSSION}

Community health workers in primary care focus on core functions that cluster into 3 roles. This categorization expands prior work in community and global settings $\mathrm{s}^{5,7,8}$ and informs future design of primary care. Practices that embed CHW-PCs could enhance care while enriching the understanding of patients' situations and needs..$^{29,38}$ Our search strategy and heterogeneity in study designs, quality, or reporting practices, however, may have limited findings. We may have overlooked variations apparent only through unpublished sources. Nonetheless, a cost-effective workforce that includes CHW-PCs might help overburdened care teams meet the Quadruple Aim ${ }^{57}$ through community- 
Table 1. CHW-PC Functions

\begin{tabular}{|c|c|c|}
\hline Function & Definition & Examples From Included Studies \\
\hline Care coordination & $\begin{array}{l}\text { Provides information and assis- } \\
\text { tance to patients about receiving } \\
\text { care from institutions and pro- } \\
\text { viders outside of primary care }\end{array}$ & $\begin{array}{l}\text { Navigates individuals at risk for coronary heart disease by making medical referrals } \\
\text { to local clinics and health care providers } 23 \\
\text { Meets with patients following each clinic appointment to help direct them to the } \\
\text { laboratory or to other appointments } 20\end{array}$ \\
\hline Health coaching & $\begin{array}{l}\text { Provides self-management support } \\
\text { to patients through counseling } \\
\text { involving collaborative goal } \\
\text { setting, problem solving, and } \\
\text { action planning }\end{array}$ & $\begin{array}{l}\text { Helps patients design action plans to achieve goals chosen by the patient }{ }^{47} \\
\text { Contacts patients, educating them about smoking cessation resources, motivating } \\
\text { them using motivational interviewing techniques, and helping them decide which } \\
\text { treatment to pursue }{ }^{46}\end{array}$ \\
\hline $\begin{array}{l}\text { Providing social } \\
\text { support }\end{array}$ & $\begin{array}{l}\text { Provides a supportive, but non- } \\
\text { therapeutic relationship, such as } \\
\text { peer-based informational, emo- } \\
\text { tional, or instrumental support }\end{array}$ & $\begin{array}{l}\text { Advocates on behalf of patients by serving as "culture brokers"50 } \\
\text { Provides emotional support, validates patients' feelings, asks open-ended ques- } \\
\text { tions, and listens reflectively } \\
\text { Leads walking club and assists with group peer support meetings focused on cop- } \\
\text { ing with life with chronic disease, stress management, group empowerment, and } \\
\text { other group-selected activities }\end{array}$ \\
\hline Health assessment & $\begin{array}{l}\text { Performs clinical assessments } \\
\text { within or outside of clinic } \\
\text { appointments }\end{array}$ & $\begin{array}{l}\text { Performs quarterly clinical assessments of } \mathrm{A}_{1,} \text {, blood pressure, weight, and foot con- } \\
\text { dition (eg, visual and monofilament assessment) } \\
\text { Interviews individuals about their health concerns, including survival and social } \\
\text { concerns such as parental stress, nutrition, access to medical care, crime, domestic } \\
\text { violence, mental health, and substance abuse }{ }^{29}\end{array}$ \\
\hline Resource linking & $\begin{array}{l}\text { Helps patients access local services } \\
\text { using standardized resources }\end{array}$ & $\begin{array}{l}\text { Requests community-based services for transition from hospital discharge, such as } \\
\text { transportation, Meals on Wheels, and in-home supports (eg, home health aid) }{ }^{21} \\
\text { Provides links to supportive community resources and tracks referrals made to local } \\
\text { programs to address patient-identified community and policy issues affecting } \\
\text { disease management }{ }^{32}\end{array}$ \\
\hline Case management & $\begin{array}{l}\text { Assesses patients' needs and pro- } \\
\text { vides personalized assistance }\end{array}$ & $\begin{array}{l}\text { Explores each patient's specific barriers to receiving care and develops and imple- } \\
\text { ments an individualized plan to address these barriers, such as scheduling } \\
\text { appointments, resolving insurance, accompanying patients to follow-up appoint- } \\
\text { ments, and making home visits }{ }^{42} \\
\text { Identifies, trouble shoots, and responds to patients' post-discharge concerns, such } \\
\text { as reminders and transportation assistance for upcoming appointments, barriers } \\
\text { to obtaining medications, concerns that might require nurse intervention, and } \\
\text { poor understanding of self-management instructions }{ }^{21}\end{array}$ \\
\hline $\begin{array}{l}\text { Medication } \\
\text { management }\end{array}$ & $\begin{array}{l}\text { Provides limited medication } \\
\text { reconciliation without making } \\
\text { recommendations }\end{array}$ & $\begin{array}{l}\text { Counsels patients on medication adherence, uses physician-approved protocols to } \\
\text { assist patients in home titration of antihypertensive medication, and notifies phy- } \\
\text { sician to fax prescription to the pharmacy } \\
\text { Assists with pharmacy activities, including helping patients obtain medication refills } \\
\text { for chronic health problems }{ }^{24}\end{array}$ \\
\hline $\begin{array}{l}\text { Remote primary } \\
\text { care }\end{array}$ & $\begin{array}{l}\text { Provides limited primary care } \\
\text { services in remote areas (eg, first } \\
\text { aid, simple chronic disease care, } \\
\text { follow-up care) }\end{array}$ & $\begin{array}{l}\text { Provides emergency care, routine clinical services, laboratory screenings, } \\
\text { physical examinations, preventive health assessments and follow-up on call } \\
24 \text { hours a day } 28 \\
\text { Provides all primary care in their community in consultation with a remote physi- } \\
\text { cian who calls regularly to elicit descriptions of patient signs and symptoms and } \\
\text { to provide specific instructions for care }{ }^{31}\end{array}$ \\
\hline Follow-up & $\begin{array}{l}\text { Monitors patients outside of office } \\
\text { visits }\end{array}$ & $\begin{array}{l}\text { Makes weekly telephone calls to patients to discuss overall well-being, adherence to } \\
\text { action plans, and blood pressure values }{ }^{25} \\
\text { Tracks patients overdue for colorectal cancer screening by calling or meeting } \\
\text { patients in the health center }{ }^{44}\end{array}$ \\
\hline Administration & $\begin{array}{l}\text { Provides front desk reception (eg, } \\
\text { data entry) }\end{array}$ & $\begin{array}{l}\text { Updates patients' medical records with colorectal cancer screening results } \\
\text { Assists in appointment scheduling, responding to patients concerns and updates } \\
\text { contact info }{ }^{21}\end{array}$ \\
\hline $\begin{array}{l}\text { Targeted health } \\
\text { education }\end{array}$ & $\begin{array}{l}\text { Provides information and didactic } \\
\text { skills training to patients with } \\
\text { specific health needs }\end{array}$ & $\begin{array}{l}\text { Makes home visits to deliver curriculum with hands-on activities focused on type } 2 \\
\text { diabetes, its complications, nutrition, physical activity, blood glucose self-monitor- } \\
\text { ing, adherence to medications and medical appointments, and mental health }{ }^{41} \\
\text { Educates patients about diabetes and the importance of blood glucose control, } \\
\text { medication adherence, diet, and exercise }{ }^{33}\end{array}$ \\
\hline $\begin{array}{l}\text { Health literacy } \\
\text { support }\end{array}$ & $\begin{array}{l}\text { Helps patients understand medical } \\
\text { advice and recommendations, } \\
\text { including translation services }\end{array}$ & $\begin{array}{l}\text { Clarifies questions stemming from patients' encounters with health care providers, } \\
\text { acts as an interpreter to enhance communication between patients and providers, } \\
\text { reinforces teaching provided by health care providers }{ }^{49} \\
\text { Assists patients in reading medical forms to address limited functional literacy }{ }^{50}\end{array}$ \\
\hline
\end{tabular}


based clinical services, resource connections, and health education and coaching.

Findings carry practical insights that extend current guidance ${ }^{10,58-61}$ for system and clinic administrators in planning diverse ways to incorporate CHW-PCs, such as devoted workspace. ${ }^{62,63}$ Home visits may extend the clinic's reach, but require new strategies for remote supervision and technology access ${ }^{64,65}$ Decisions about how to best utilize CHW-PCs depend on needs of patients and care teams, clinical workflows, financial viability, and addressing practice burdens while facilitating performance ${ }^{66,67}$ and cost-savings. ${ }^{68}$ Increasing

Table 2. CHW-PC Roles

\section{Study}

\begin{tabular}{|c|c|c|c|c|c|c|c|c|c|c|c|}
\hline 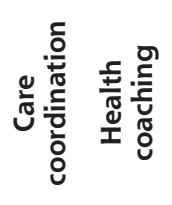 & 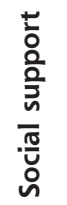 & 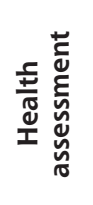 & 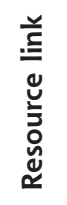 & 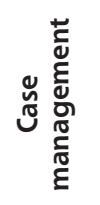 & 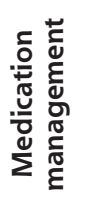 & 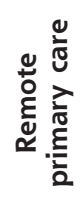 & & & & & 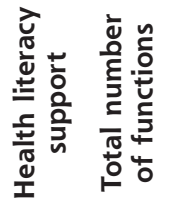 \\
\hline
\end{tabular}

Cluster 1: Clinical services $(n=11)$

Burns et al, ${ }^{21} 2014$

Findley et $\mathrm{al}^{22} 2014$

Krantz et al, ${ }^{23,53} 2013$

Golnick et al, ${ }^{24} 2012$

Margolius et al, ${ }^{25,55} 2012$

Battaglia et al, ${ }^{26} 2012$

Naar-King et al, 272009

Sherer et al, 28,56 1994

Swider et al, $^{29} 1990$

Deuschle et al, ${ }^{30} 1983$

Hudson et al, ${ }^{31} 1973$

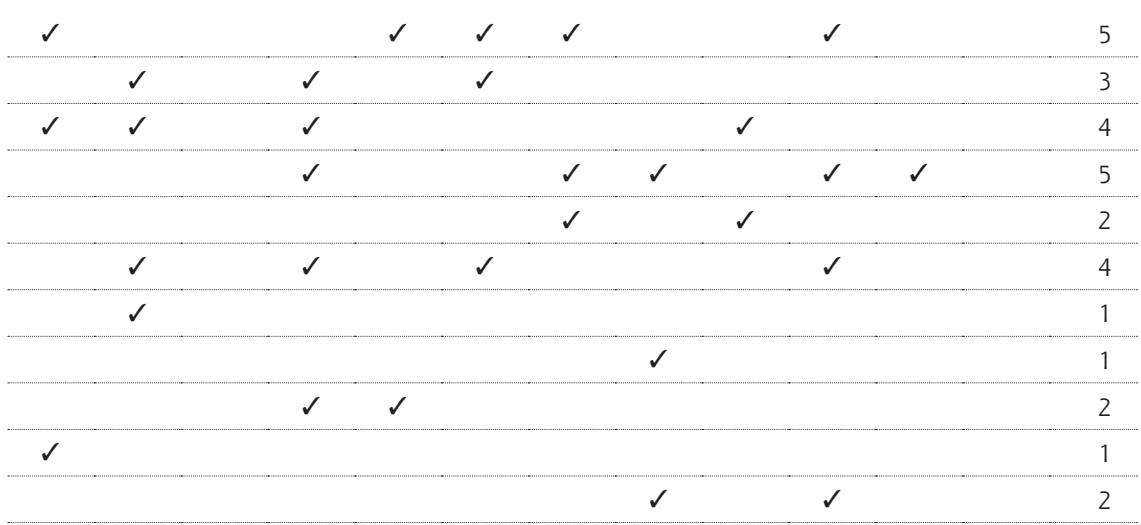

Cluster 2: Community resource connections $(n=8)$

Wennerstrom et al, ${ }^{32} 2015$

Collinsworth et al, ${ }^{33,34} 2013 ; 2014$

Volkmann et al, ${ }^{35} 2011$

Waitzkin et al, ${ }^{36} 2011$

Holtrop et $\mathrm{al}_{1}{ }^{37} 2008$

Thompson et $\mathrm{al}^{38} 2007$

Adelman et al, ${ }^{39} 2005$

Torrey et al, ${ }^{40,54} 1973$

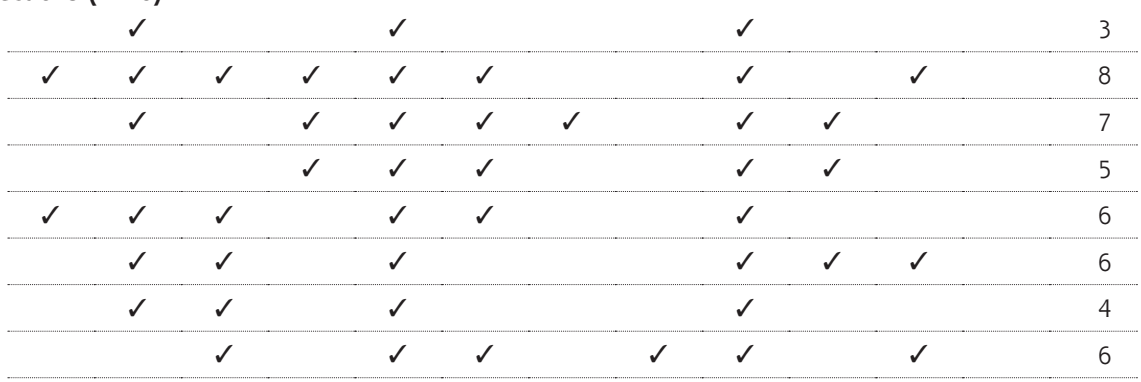

Cluster 3: Health education and coaching $(n=11)$

Perez-Escamilla et al, ${ }^{41} 2015$

Percac-Lima et al, ${ }^{42} 2015$

Matiz et al, ${ }^{43} 2014$

Percac-Lima et al, 44,51 2014

Kangovi et al, ${ }^{45} 2014$

Lasser et al, ${ }^{46} 2013$

Thom et al, ${ }^{47,52} 2013$

Adair et al, 202012

Otero-Sabogal et al, ${ }^{48} 2010$

McElmurry et al, ${ }^{49} 2009$

Poland et al, ${ }^{50} 1991$

Total number of studies

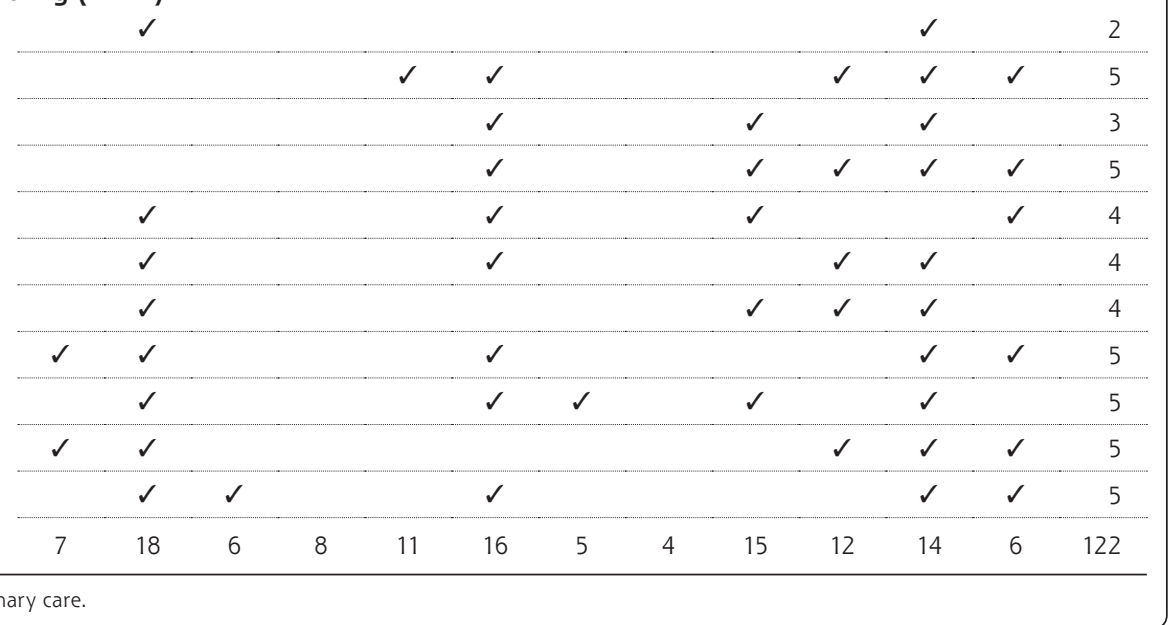


the presence of CHW-PCs also requires training and clinical integration necessary to build this new workforce, ${ }^{59,69}$ including certification, ${ }^{58}$ health information technology, and clinical oversight for the breadth of contributions CHW-PCs offer.

\section{To read or post commentaries in response to this article, see it} online at http://www.AnnFamMed.org/content/16/3/240.

Key words: community health workers; primary health care; patient care team

Submitted September 4, 2017; submitted, revised, December 13, 2017; accepted January 11, 2017.

Funding support: Group Health Foundation Partnership for Innovation Fund.

Acknowledgments: Group Health Foundation Partnership for Innovation Fund supported this work. We thank Dr Paula Lozano, Katie Bell, and Dr Sean McNee for their thoughtful feedback on this manuscript.

Supplementary materials: Available at http://www.AnnFamMed. org/content/16/3/240/suppl/DC1/.

\section{References}

1. Lewin S, Munabi-Babigumira S, Glenton C, et al. Lay health workers in primary and community health care for maternal and child health and the management of infectious diseases. Cochrane Database Syst Rev. 2010;(3):CD004015.

2. Viswanathan M, Kraschnewski JL, Nishikawa B, et al. Outcomes and costs of community health worker interventions: a systematic review. Med Care. 2010;48(9):792-808.

3. Gibbons MC, Tyus NC. Systematic review of U.S.-based randomized controlled trials using community health workers. Prog Community Health Partnersh. 2007;1(4):371-381.

4. Page-Reeves J, Kaufman W, Bleecker M, et al. Addressing social determinants of health in a clinic setting: the WellRx Pilot in Albuquerque, New Mexico. J Am Board Fam Med. 2016;29(3):414-418.

5. United States Department of Health and Human Services, Health Resources and Services Administration, Bureau of Health Professions. Community health worker national workforce study. https:// bhw.hrsa.gov/sites/default/files/bhw/nchwa/projections/communityhealthworkforce.pdf. Published Mar 2007. Accessed Dec 13, 2017.

6. Fisher EB, Ayala GX, Ibarra L, et al; Peers for Progress Investigator Group. Contributions of peer support to health, health care, and prevention: papers from peers for progress. Ann Fam Med. 2015; 13(Suppl 1):S2-S8.

7. American Public Health Association. Support for community health workers to increase health access and to reduce health inequities. https://www.apha.org/policies-and-advocacy/public-healthpolicy-statements/policy-database/2014/07/09/14/19/support-forcommunity-health-workers-to-increase-health-access-and-to-reducehealth-inequities. Published Nov 2009. Accessed Dec 13, 2017.

8. Koch E. A Summary of the National Community Health Advisor Study: Weaving the Future. Tucson, AZ: University of Arizona Health Sciences Center; 1998.

9. Wagner $\mathrm{EH}$. The role of patient care teams in chronic disease management. BMJ. 2000;320(7234):569-572.

10. Balcazar H, Rosenthal EL, Brownstein JN, Rush CH, Matos S, Hernandez L. Community health workers can be a public health force for change in the United States: three actions for a new paradigm. Am J Public Health. 2011;101(12):2199-2203.
11. Love MB, Gardner K, Legion V. Community health workers: who they are and what they do. Health Educ Behav. 1997;24(4):510-522.

12. Brownstein JN, et al. Community health workers "101" for primary care providers and other stakeholders in health care systems. J Ambul Care Manage. 2011;34(3):210-220.

13. Moher D, Liberati A, Tetzlaff J, Altman DG, PRISMA Group. Preferred reporting items for systematic reviews and meta-analyses: the PRISMA statement. Ann Intern Med. 2009;151(4):264-269, W64.

14. Popay J, ed. Moving Beyond Effectiveness in Evidence Synthesis: Methodological Issues in the Synthesis of Diverse Sources of Evidence. London, UK: National Institute for Health and Clinical Excellence; 2006.

15. Khanassov V, Vedel I, Pluye P. Barriers to implementation of case management for patients with dementia: a systematic mixed studies review. Ann Fam Med. 2014;12(5):456-465.

16. Souto RQ, Khanassov V, Hong QN, Bush PL, Vedel I, Pluye P. Systematic mixed studies reviews: updating results on the reliability and efficiency of the Mixed Methods Appraisal Tool. Int J Nurs Stud. 2015;52(1):500-501.

17. Paul CL. A modified delphi approach to a new card sorting methodology. J Usability Stud. 2008;4(1):7-30.

18. Hartigan JA, Wang MA. Algorithm AS 136: A K-Means clustering algorithm. Journal of the Royal Statistical Society, Series C. 1979;28(1): 100-108.

19. Rousseeuw PJ. Silhouettes: a graphical aid to the interpretation and validation of cluster analysis. J Comput Appl Math. 1987;20:53-65.

20. Adair R, Christianson J, Wholey DR, et al. Care guides: employing nonclinical laypersons to help primary care teams manage chronic disease. J Ambul Care Manage. 2012;35(1):27-37.

21. Burns ME, Galbraith AA, Ross-Degnan D, Balaban RB. Feasibility and evaluation of a pilot community health worker intervention to reduce hospital readmissions. Int J Qual Health Care. 2014;26(4): 358-365.

22. Findley S, Matos S, Hicks A, Chang J, Reich D. Community health worker integration into the health care team accomplishes the triple aim in a patient-centered medical home: a Bronx tale. J Ambul Care Manage. 2014;37(1):82-91.

23. Krantz MJ, Coronel SM, Whitley EM, Dale R, Yost J, Estacio RO. Effectiveness of a community health worker cardiovascular risk reduction program in public health and health care settings. Am J Public Health. 2013;103(1):e19-e27.

24. Golnick C, Asay E, Provost E, et al. Innovative primary care delivery in rural Alaska: a review of patient encounters seen by community health aides. Int J Circumpolar Health. 2012;71:10.3402/ijch. v71i0.18543.

25. Margolius D, Bodenheimer T, Bennett $H$, et al. Health coaching to improve hypertension treatment in a low-income, minority population. Ann Fam Med. 2012;10(3):199-205.

26. Battaglia TA, McCloskey L, Caron SE, et al. Feasibility of chronic disease patient navigation in an urban primary care practice. J Ambul Care Manage. 2012;35(1):38-49.

27. Naar-King S, Outlaw A, Green-Jones M, Wright K, Parsons JT. Motivational interviewing by peer outreach workers: a pilot randomized clinical trial to retain adolescents and young adults in HIV care. AIDS Care. 2009;21(7):868-873.

28. Sherer JL. Bringing providers to the people. Alaska and a Florida county blaze new trails in non-physician care delivery. Hosp Health Netw. 1994;68(3):56-60.

29. Swider SM, McElmurry BJ. A women's health perspective in primary health care: A nursing and community health worker demonstration project in urban America. Fam Community Health. 1990;13(3):1-17.

30. Deuschle KW. Community-oriented primary care: lessons learned in three decades. J Community Health. 1982;8(1):13-22.

31. Hudson HE, Parker EB. Medical communication in Alaska by satellite. N Engl J Med. 1973;289(25):1351-1356. 
32. Wennerstrom A, Bui T, Harden-Barrios J, Price-Haywood EG. Integrating community health workers into a patient-centered medical home to support disease self-management among Vietnamese Americans: lessons learned. Health Promot Pract. 2015;16(1):72-83.

33. Collinsworth AW, Vulimiri M, Schmidt KL, Snead CA. Effectiveness of a community health worker-led diabetes self-management education program and implications for CHW involvement in care coordination strategies. Diabetes Educ. 2013;39(6):792-799.

34. Collinsworth A, Vulimiri M, Snead C, Walton J. Community health workers in primary care practice: redesigning health care delivery systems to extend and improve diabetes care in underserved populations. Health Promot Pract. 2014;15(2)(Suppl):51S-61S.

35. Volkmann K. Castañares T. Clinical community health workers: linchpin of the medical home. J Ambul Care Manage. 2011;34(3):221-233.

36. Waitzkin $\mathrm{H}$, Getrich $\mathrm{C}$, Heying $\mathrm{S}$, et al. Promotoras as mental health practitioners in primary care: a multi-method study of an intervention to address contextual sources of depression. J Community Health. 2011;36(2):316-331.

37. Holtrop JS, Dosh SA, Torres T, Thum YM. The community health educator referral liaison (CHERL): a primary care practice role for promoting healthy behaviors. Am J Prev Med. 2008;35(5)(Suppl): S365-S372.

38. Thompson JR, Horton C, Flores C. Advancing diabetes selfmanagement in the Mexican American population: a community health worker model in a primary care setting. Diabetes Educ. 2007; 33(Suppl 6):159S-165S.

39. Adelman AM, Graybill M. Integrating a health coach into primary care: reflections from the Penn state ambulatory research network. Ann Fam Med. 2005;3(Suppl 2):S33-S35.

40. Torrey EF, Smith $D$, Wise $H$. The family health worker revisited: a five-year follow-up. Am J Public Health. 1973;63(1):71-74.

41. Pérez-Escamilla R, Damio G, Chhabra J, et al. Impact of a community health workers-led structured program on blood glucose control among latinos with type 2 diabetes: the DIALBEST trial. Diabetes Care. 2015;38(2):197-205.

42. Percac-Lima S, Ashburner JM, McCarthy AM, Piawah S, Atlas SJ. Patient navigation to improve follow-up of abnormal mammograms among disadvantaged women. J Womens Health (Larchmt). 2015; 24(2):138-143.

43. Matiz LA, Peretz PJ, Jacotin PG, Cruz C, Ramirez-Diaz E, Nieto AR. The impact of integrating community health workers into the patient-centered medical home. J Prim Care Community Health. 2014; 5(4):271-274.

44. Percac-Lima S. López L, Ashburner JM, Green AR, Atlas SJ. The longitudinal impact of patient navigation on equity in colorectal cancer screening in a large primary care network. Cancer. 2014;120(13): 2025-2031.

45. Kangovi S, Mitra N, Grande D, et al. Patient-centered community health worker intervention to improve posthospital outcomes: a randomized clinical trial. JAMA Intern Med. 2014;174(4):535-543.

46. Lasser KE, Kenst KS, Quintiliani LM, et al. Patient navigation to promote smoking cessation among low-income primary care patients: a pilot randomized controlled trial. J Ethn Subst Abuse. 2013;12(4): 374-390.

47. Thom DH, Ghorob A, Hessler D, De Vore D, Chen E, Bodenheimer TA. Impact of peer health coaching on glycemic control in lowincome patients with diabetes: a randomized controlled trial. Ann Fam Med. 2013;11(2):137-144.

48. Otero-Sabogal R, Arretz D, Siebold S, et al. Physician-community health worker partnering to support diabetes self-management in primary care. Qual Prim Care. 2010;18(6):363-372.

49. McElmurry BJ, McCreary LL, Park CG, et al. Implementation, outcomes, and lessons learned from a collaborative primary health care program to improve diabetes care among urban Latino populations. Health Promot Pract. 2009;10(2):293-302.
50. Poland ML, Giblin PT, Waller JB Jr, Bayer IS. Development of a paraprofessional home visiting program for low-income mothers and infants. Am J Prev Med. 1991;7(4):204-207.

51. Percac-Lima S, Grant RW, Green AR, et al. A culturally tailored navigator program for colorectal cancer screening in a community health center: a randomized, controlled trial. J Gen Intern Med. 2009:24(2):211-217.

52. Ghorob A, Vivas MM, De Vore $D$, et al. The effectiveness of peer health coaching in improving glycemic control among low-income patients with diabetes: protocol for a randomized controlled trial. BMC Public Health. 2011;11(1):208-214.

53. Drisko J, Everhart RM, Samuels BA. Standardized academic education prepares competent community health workers. Am J Health Stud. 2007;22(2):121-126.

54. Wise HB, Torrey EF, McDade A, Perry G, Bograd H. The family health worker. Am J Public Health Nations Health. 1968;58(10): 1828-1838.

55. Bennett H, Laird K, Margolius D, Ngo V, Thom DH, Bodenheimer $T$. The effectiveness of health coaching, home blood pressure monitoring, and home-titration in controlling hypertension among lowincome patients: protocol for a randomized controlled trial. BMC Public Health. 2009;9(1):456-462.

56. US Government Accountability Office, Special Committee on Aging. Health care access: Innovative programs using nonphysicians. Report No: HRD-93-128. http://www.gao.gov/products/149892. Published Aug 1993. Accessed Dec 13, 2017.

57. Bodenheimer T, Sinsky C. From triple to quadruple aim: care of the patient requires care of the provider. Ann Fam Med. 2014;12(6): 573-576.

58. Brownstein JN, Hirsch GR. Transforming health care systems: CHWs as the glue in multidisciplinary teams. J Ambul Care Manage. 2017; 40(3):179-182.

59. Singh P, Chokshi DA. Community health workers-a local solution to a global problem. N Engl J Med. 2013;369(10):894-896.

60. Rosenthal EL, Brownstein JN, Rush CH, et al. Community health workers: part of the solution. Health Aff (Millwood). 2010;29(7):1338-1342.

61. Bodenheimer T, Laing BY. The teamlet model of primary care. Ann Fam Med. 2007;5(5):457-461.

62. Garg A, Marino M, Vikani AR, Solomon BS. Addressing families' unmet social needs within pediatric primary care: the health leads model. Clin Pediatr (Phila). 2012;51(12):1191-1193.

63. Ferrante JM, Cohen DJ, Crosson JC. Translating the patient navigator approach to meet the needs of primary care. J Am Board Fam Med. 2010;23(6):736-744.

64. Allen C, Brownstein JN, Jayapaul-Philip B, Matos S, Mirambeau A. Strengthening the effectiveness of state-level community health worker initiatives through ambulatory care partnerships. J Ambul Care Manage. 2015;38(3):254-262.

65. Li J, Alem L. Supporting distributed collaborations between mobile health workers and expert clinicians in home care. In: Proceedings of $\mathrm{CHI}^{\prime} 13$ Extended Abstracts on Human Factors in Computing Systems; April 27-May 2, 2013; Paris, France. p 493-498.

66. Bodenheimer T, Ghorob A, Willard-Grace R, Grumbach K. The 10 building blocks of high-performing primary care. Ann Fam Med. 2014;12(2):166-171.

67. Margolius $D$, Bodenheimer T. Transforming primary care: from past practice to the practice of the future. Health Aff (Millwood). 2010; 29(5):779-784.

68. Moffett ML, Kaufman A, Bazemore A. Community health workers bring cost savings to patient-centered medical homes. J Community Health. 2018;43(1):1-3.

69. Brown C, Hennings J, Caress AL, Partridge MR. Lay educators in asthma self management: reflections on their training and experiences. Patient Educ Couns. 2007;68(2):131-138. 